\title{
Retraction Note to: Two-Dimensional Simulation of Percolation Structure in Two-Phase Composites
}

\author{
Soon-Gi Shin ${ }^{1}$
}

Published online: 26 February 2018

(c) The Korean Institute of Metals and Materials 2018

\section{Retraction Note to: Metals and Materials International, Vol. 13, No. 5 (2007), pp. 385-389 https://doi.org/10.1007/BF03027872}

This article [1] has been retracted at the request of the Editor-in-Chief. Concerns were raised regarding substantial duplications with previous articles published in other journals. After a thorough analysis, we conclude that the concerns are valid. The article contains sections that substantially overlap with the following published article [2] (amongst others). S.-G. Shin has not responded to correspondence from the Editor about this retraction.

1. "Two-Dimensional Simulation of Percolation Structure in Two-Phase Composites" S.-G. Shin, Mat. Mater. Int., Vol. 13, Issue 5, pp. 385-389 (2007).

2. "Computer Simulation of Percolation Structure in Composites" A. Ishida, H. Matsubara, K. Furukawa, M. Miyayama, and H. Yanagida, J. Ceram. Soc. Jpn. 103, 996 (1995).

Soon-Gi Shin

ssg@kangwon.ac.kr

1 Division of Advanced Materials and Chemical Engineering, Kangwon National University, 1, Joongang-ro, Samcheok-si, Gangwon 245-711, Korea 